\title{
Thromboembolic or atherosclerotic? Optical coherence tomography in determining the cause of myocardial infarction with ST-segment elevation
}

\author{
Sylwia Iwańczyk¹, Wojciech J. Skorupski', Sławomir Kępski², Marek Grygier¹, Maciej Lesiak \\ 1 1st Department of Cardiology, Poznan University of Medical Sciences, Poznań, Poland \\ 2 Roman Ostrzycki Provincial Integrated Hospital, Konin, Poland
}

Correspondence to: Sylwia Iwańczyk, MD, 1st Department of Cardiology, Poznan University of Medical Sciences, ul. Długa 1/2, 61-848 Poznań, Poland phone: +48618549222, email: syl.iwanczyk@gmail.com Received: May 6, 2020. Revision accepted: July 1, 2020. Published online: July 8, 2020. Kardiol Pol. 2020; 78 (10): 1045-1046 doi:10.33963/KP.15499 Copyright by the Author(s), 2020
In the last years, due to its high image resolution, optical coherence tomography (OCT) has been largely used in the assessment of atherosclerotic plaque features. The results obtained by the OCT imaging may determine the choice of optimal treatment technique., ${ }^{1,2}$

A 55-year-old man with no history of any cardiovascular disease was admitted to the hospital with typical severe retrosternal pain. Acute myocardial infarction with ST-segment elevation (STEMI) was diagnosed. Immediate coronary angiography showed large thrombus causing subtotal occlusion in the medial and distal segments of the right coronary artery (RCA) with TIMI flow 2 and the occlusion of peripheral segment of posterior descending artery by the embolic material (FIGURE 1B). Due to the maintained flow through the artery and a high risk of progression of peripheral thromboembolism because of massive thrombosis, the operator did not perform aspiration thrombectomy and decided to induce a bolus $(7.9 \mathrm{ml})$ and a prolonged infusion therapy with a glycoprotein IIb / IIIa inhibitor, eptifibatide, parallel with a heparin infusion. Triple antiplatelet therapy with ticagrelor and acetylsalicylic acid (ASA) was continued. Echocardiography, performed after the procedure, showed no contraction abnormalities of the left ventricle with good ejection fraction of $60 \%$, but also revealed right ventricular and pulmonary trunk enlargement. Transesophageal echocardiography showed a 21-mm sinus venous atrial septal defect (ASD) with a left-to-right leak, suggesting an embolic cause of STEMI (Supplementary material, Figure S1). Control coronary angiography after 9 days showed resorption of most of the thrombus in the medial segment with TIMI 3 flow to the end of the posterior descending artery, but the thrombus was still visible in the distal segment of the RCA (FIGURE 1C). To differentiate the origin of the material, that is, embolic or coronary, atherosclerotic plaque rapture OCT was performed. It revealed atherosclerotic changes with plaque rapture and unorganized mural thrombosis in the distal part of the vessel (FIGURE 1A). Due to a promising initial result of anticoagulation, nonsignificant atherosclerotic narrowing of the artery, and a high risk of peripheral thromboembolism, it was decided to prolong the triple antithrombotic therapy with clopidogrel, rivaroxaban $15 \mathrm{mg} / \mathrm{d}$, and ASA without stenting. Percutaneous closure in a patient with hemodynamically significant sinus venous ASD is not recommended, so the patient was preliminary qualified to surgery. The procedure was postponed and dependent on the patency of the RCA after 6 months of triple antithrombotic therapy. After 6 months, coronary angiography with OCT revealed organized thrombus significantly narrowing the distal segment of the RCA (FIGURE 1D). The decision to perform revascularization was made. Successful stent implantation was performed (FIGURE 1E). Due to the presence of the thrombus, the antithrombotic therapy was continued but changed to warfarin, clopidogrel, and ASA. Because cardiac surgeons requested 

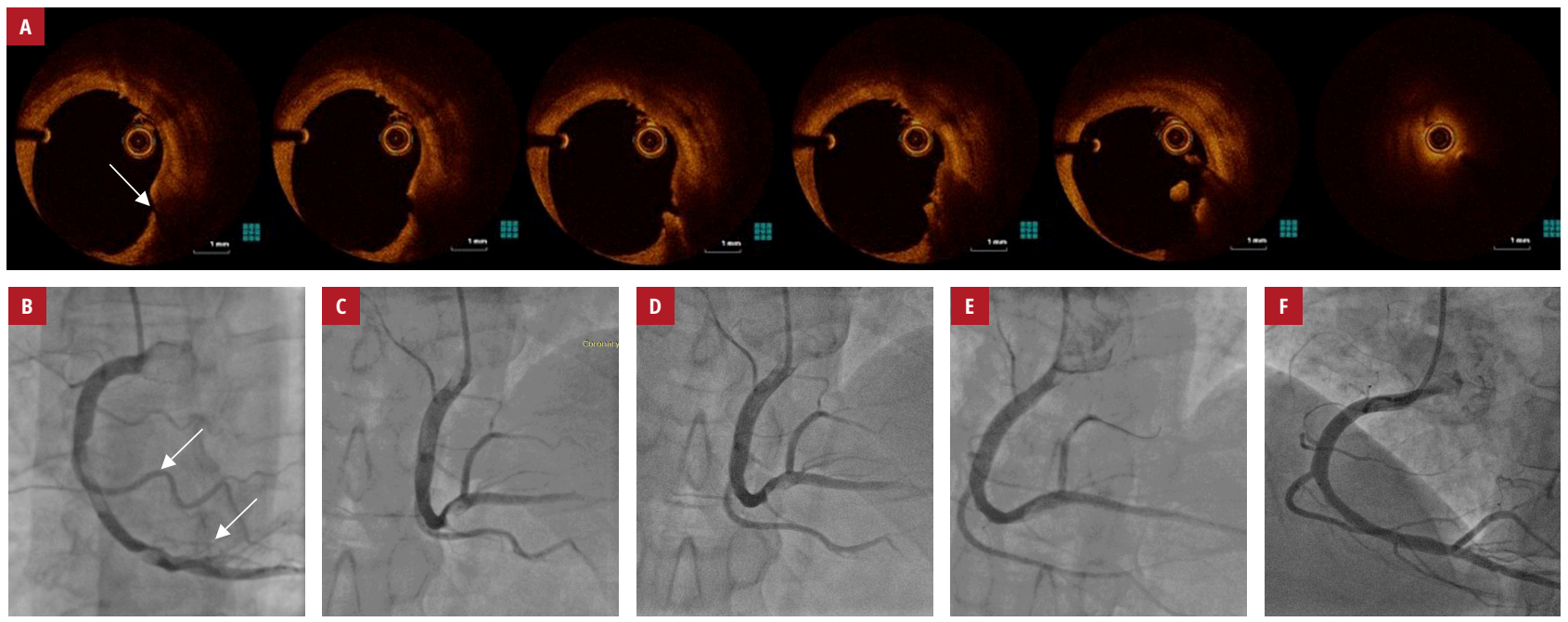

FIGURE 1 A - optical coherence tomography (OCT) cross sections of the mid and distal segment of the right coronary artery (RCA) with ruptured atherosclerotic plaque (arrow) and growing thrombus filling the lumen of the vessel in the distal segments; $\mathbf{B}$ - first angiography of the RCA with visible thrombus in the mid and distal segments (arrows); C - control angiography of the RCA after 9 days; D - angiographic view of the RCA after 6 -month follow-up before percutaneous coronary intervention with stent implantation; $\mathbf{E}$ - angiographic view of the RCA after percutaneous coronary intervention with stent implantation in the distal segment; F - final angiographic view of the RCA after 12-month follow-up

to prove the full patency of the RCA before surgery, next coronary angiography was performed. It showed organized mural thrombosis without significant narrowing of the RCA (FIGURE 1F). Optical coherence tomography confirmed further major regression of thrombus (Supplementary material, Figure S2), so finally, the patient was qualified for elective ASD surgery only.

Optical coherence tomography enabled proper diagnostic workup of the cause of STEMI as well as determined the choice of treatment in all subsequent stages.

\section{SUPPLEMENTARY MATERIAL}

Supplementary material is available at www.mp.pl/kardiologiapolska.

\section{ARTICLE INFORMATION}

\section{CONFLICT OF INTEREST None declared.}

OPEN ACCESS This is an Open Access article distributed under the terms of the Creative Commons Attribution-NonCommercial-NoDerivatives 4.0 International License (CC BY-NC-ND 4.0), allowing third parties to download articles and share them with others, provided the original work is properly cited, not changed in any way, distributed under the same license, and used for noncommercial purposes only. For commercial use, please contact the journal office at kardiologiapolska@ptkardio.pl.

HOW TO CITE IwańczykS, Skorupski WJ, KępskiS, et al. Thromboembolic or atherosclerotic? Optical coherence tomography in determining the cause of myocardial infarction with ST-segment elevation. Kardiol Pol. 2020; 78: 1045-1046. doi:10.33963/KP.15499

\section{REFERENCES}

1 Ino Y, Kubo T, Tanaka A, et al. Difference of culprit lesion morphologies between ST-segment elevation myocardial infarction and non-ST-Segment elevation acute coronary syndrome: an optical coherence tomography study. J Am Coll Cardiol Intv. 2011; 4: 76-82.

2 Kranjec I, Mrevlje B, Legutko J, et al. Optical coherence tomography: guided primary percutaneous coronary intervention in acute myocardial infarction. A bridge too far? Kardiol Pol. 2015; 73: 309-316. 